\title{
The Division of Labor, Investment, and Capital
}

\author{
Xiaokai Yang \\ CID Working Paper No. 8 \\ March 1999
}

(C) Copyright 1999 Xiaokai Yang,

and the President and Fellows of Harvard College
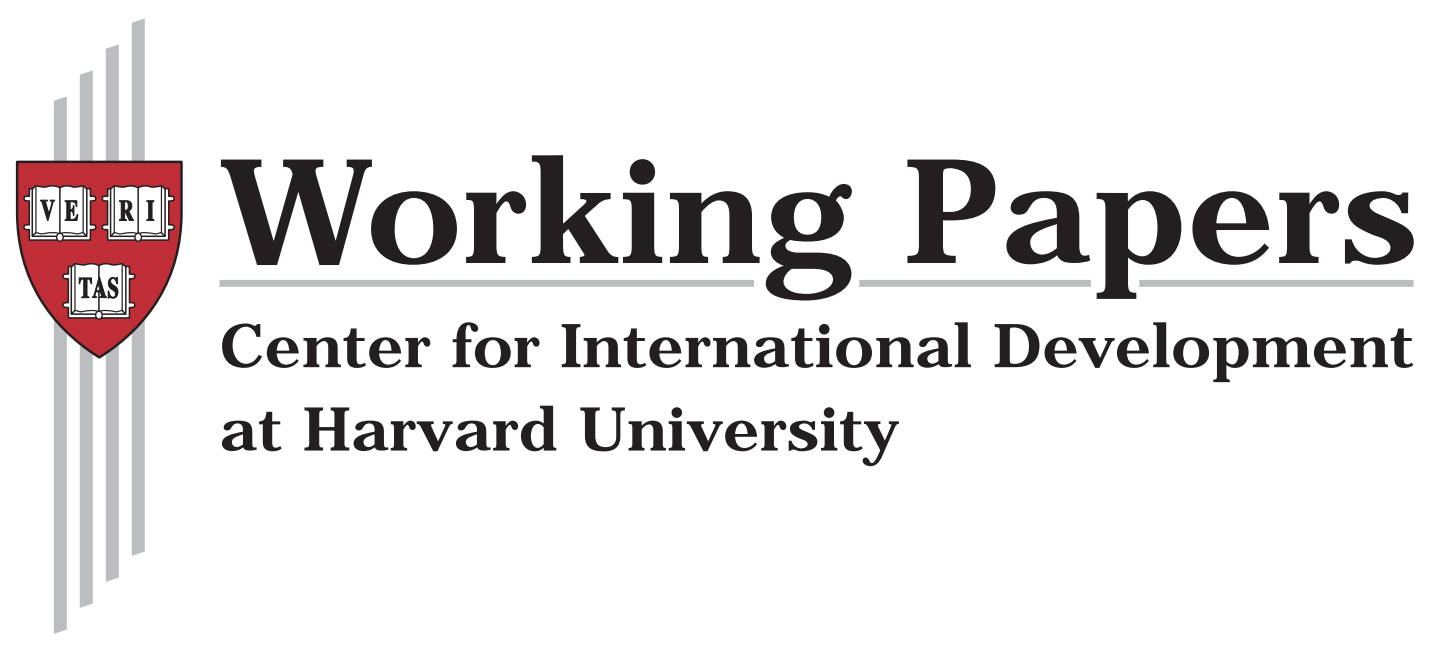


\title{
The Division of Labor, Investment, and Capital
}

\author{
Xiaokai Yang*
}

\begin{abstract}
This paper uses a dynamic general equilibrium model based on corner solutions to formalize the classical theory of investment and capital which considers investment to be a vehicle for developing a high level of division of labor in roundabout productive activities. If it takes time for a specialist producer of tractors to learn the right method in producing commercially viable tractors, specialization in producing tractors is infeasible in the absence of investment in terms of consumption goods which are consumed by the specialist producer of tractor before he can sell tractors. If specialized learning by doing can speed up accumulation of professional knowledge so that roundabout productive machines becomes cheap, such investment for increasing the level of division of labor in roundabout productive activities will speed up economic growth. Due to the tradeoff between economies of specialized learning by doing and transaction costs, the model can be used to investigate the effects of a change in the transaction cost coefficient, which can be affected by policy, the legal system, and urbanization, on the evolution of division of labor, on real interest rates, and on saving rate.
\end{abstract}

JEL codes: D23, D50, D90, O12

Keywords: Criticism of investment fundamentalism, criticism of technology fundamentalism, Smithian model of investment, Smithian growth mechanism, evolution in division of labor

Xiaokai Yang is a Research Fellow at the Center for International Development. His research interests include equilibrium network of division of labor, endogenous comparative advantages, inframarginal analysis of patterns of trade and economic development.

\footnotetext{
* The author is grateful to the participants of International Conference on Dynamic Modeling and of the seminars at University of London, Monash University and Australian National University, and the two referees for Metroeconomica for their comments and criticisms. Special thanks are due to Don Snodgrass, Yew-Kwang Ng and Jeff Borland for helpful discussion. I am responsible for the remaining errors.
} 


\title{
The Division of Labor, Investment, and Capital
}

\author{
Xiaokai Yang
}

\section{INTRODUCTION}

The purpose of the current paper is to use a dynamic general equilibrium model to assess "saving and investment fundamentalism" which claims an unconditional positive relationship between current saving and future productivity. This investment fundamentalism is taken as granted in the growth models of Ramsey (1928), Solow (1956, 1964), Lucas (1988), Romer (1986, 1987, 1990), and Grossman and Helpman (1989, 1990, 1991). The specification of production functions in all the models implies that saving and investment will increase productivity in the future by increasing capital per person.

We may however ask why productivity in the future can be increased by saving today. This positive relationship did not exist two thousand years ago. For instance, two thousand years ago, peasants invested corn seeds each year. But that investment could only maintain simple reproduction without much increase in productivity. Also, Chinese peasants invested in houses which were completely self-provided in the 1970s. Productivity based on such investment in durable houses was extremely low (Yang, Wang, and Wills, 1992).

To the question Lucas and Romer will respond by pointing to human capital generated by saving and investment. However, we will again use the Chinese case to argue that investment in human capital and education does not necessarily lead to an increase in productivity. Chinese people have a special preference for saving and for investment in education. However, this had not generated significant productivity increases until the modern school and university system was introduced into China at the end of the 19th century. In traditional Chinese schools, there was no division of labor between teachers. Each teacher taught students a broad range of knowledge, from literature to philosophy. But in a modern university, there is a very high level of division of labor between different specialist teachers and between different specialized colleges. Also educated individuals are very specialized in their professions after their graduation from universities. It is the high level of division of labor that ensures high productivity in providing education, so that investment in education can contribute significantly to productivity progress. Recent empirical evidences support our observation. Printchett (1997) shows that empirical evidences from macro 
data reject the unconditional positive relationship between educational capital and the rate of growth of output per worker, despite the positive effects of education on earnings from micro data.

To our question above, Grossman and Helpman might respond by pointing to investment in research and development. However, Marshall attributed the invention of the steam engine by Boulton and Watt to a deep division of labor in the inventing activities (1890, p. 256). Edison's experience is another evidence for the implication of the division of labor for successful inventions. Not only Edison did himself specialize in inventing electrical machines for most of his life, but he also organized a professional research institution with more than one hundred employees who specialized in different inventing activities (Josephson, 1959).

The observation implies that investment in physical capital goods, in education, or in research would not automatically increase productivity in the future if the investment were not used to develop the right level and pattern of division of labor. Hence, the essential question around the notion of capital is not so much as to how much we invest and save, but rather as to what level and pattern of division of labor are used to invest in machines, education, and research.

The recent empirical evidences that reject so called scale effect associated with the positive relationship between current saving and future productivity support our observation. Type-I scale effect exists if there is a positive relationship between growth rates in per capita GDP and investment rates. The AK model generates type-I scale effect which is conclusively rejected by empirical evidence (see Jones, 1995a) ${ }^{1}$. This suggests that "the AK models do not provide a good description of the driving forces behind growth" (Jones, 1995a, pp. 508-509). The R\&D based model generates a positive relationship between the growth rates in per capita GDP and the level of resources devoted to R\&D, referred to as type-II scale effect ${ }^{2}$. Type-II scale effect is also rejected by the empirical observations (Jones, 1995b).

Jones (1995b) and Alwyn Young (1998) have developed two models to salvage the R\&D-based model, but the modified models still have type-III scale effect, a positive relationship between the growth rate in per capita GDP and the growth rate of population, which

\footnotetext{
${ }^{1}$ According to Jones (1995a,b) and Barro and Sala-i-Martin (1995), the Romer model (1987), the Rebelo model (1991), the Barro model (1991), and the Benhabib and Jovanovic model (1991) can be considered as the AK model since their reduced forms are the same as the AK model.

2 Judd (1985), Romer (1990), Grossman and Helpman (1990, 1991), and Aghion and Howitt (1992), among others, are
} 
is also wildly at odds with the empirical evidences surveyed by Dasgupta (1995). As Jones (1995b) indicates, endogenous growth cannot be preserved if the scale effect in the R\&D-based model is eliminated. Now endogenous growth economists are busy with developing new models that can avoid scale effects. The current paper will show there is a simple way to avoid scale effects: formalize classical economic thinking on investment, division of labor, and growth.

The growth mechanisms described by most classical economists do not have the unconditional positive relationship between saving and productivity. Instead they emphasized the connection between the division of labor and investment. Smith (1776) and Allyn Young (1928) explicitly spelled out the relationship between the division of labor, investment, and capital. According to them, capital and investment is a matter of the development of division of labor in roundabout productive activities. ${ }^{3}$ If there is a division of labor between the production of final consumption goods (say food) and the production of producer goods (say tractors) and if the production of tractors takes time to complete due to, for instance, a significant fixed learning cost, then the specialist producers of tractors cannot survive in the absence of investment which is used to provide the specialists with food before they can sell tractors. Hence, capital is a vehicle for society to increase the level of division of labor in roundabout productive activities. The high level of division of labor can speed up the accumulation of knowledge through specialized learning by doing, thereby generating productivity progress.

The current paper will formalize the story of investment and capital. A dynamic general equilibrium model will be used to address the following questions. What is the relationship between capital, which relates to saving and investment, and the division of labor, which determines the extent of the market, trade dependence, and productivity? What is the mechanism that simultaneously determines the investment level and the level of division of labor and what are determinants of the equilibrium investment (saving) rate, interest rate, growth rate, and the equilibrium level of division of labor?

Our story of investment runs as follows. There are many ex ante identical consumerproducers in an economy where food can be produced out of labor alone or out of labor and

\footnotetext{
along this line.

${ }^{3}$ Smith stated (1776, p. 371) "when the division of labor has once been thoroughly introduced, the produce of a man's own labor can supply but a very small part of his occasional wants. The far greater part of them are supplied by the produce of other men's labor, which he purchases with the produce, ... of his own. But this purchase cannot be made till such time as the produce of his own labor has not only been completed, but sold. A stock of goods of different kinds, therefore, must be stored up somewhere sufficient to maintain him, and to supply him with the materials and tools of
} 
tractors. In producing each good, there are economies of specialized learning by doing. A fixed cost is incurred in the period when an individual engages in a job for the first time or when job shifting takes place. Each individual can choose between specialization and self-sufficiency. The advantage of specialization is to exploit economies of specialized learning by doing and to avoid job shifting costs. However, it increases productivity in the future at the expense of current consumption because of an increase in transaction cost caused by specialization.

Moreover, in producing a tractor, there is a significant fixed learning cost. The production of a tractor cannot be completed until the learning cost has reached a threshold level. Hence, there are tradeoffs among economies of specialized learning by doing, economies of roundaboutness, transaction costs, and fixed learning costs. Each consumer-producer maximizes total discounted utility over the two periods with respect to the level and pattern of specialization and quantities of goods consumed, produced, and traded in order to efficiently trade off one against others among the four conflicting forces.

The interactions of these tradeoffs determine the nature of the dynamic equilibrium for the economy. If the transaction cost coefficient is sufficiently great, the economy is in autarky in all periods - depending upon the level of fixed learning cost and the degree of economies of roundaboutness this may involve each individual self-providing food, or each individual selfproviding both food and tractor, or the evolution in the number of goods. If the transaction cost coefficient is sufficiently small and economies of specialized learning by doing and of roundaboutness are significant, in the dynamic equilibrium the economy is in a market structure in which individuals specialize in the production of either tractor or food and trade occurs. For the division of labor there are two patterns of investment and saving. If the fixed learning cost in producing tractor is not large, each individual will sacrifice consumption in period 1 to pay transaction costs in order to increase the level of division of labor, so that productivity in period 2 can be increased. This is a self-saving mechanism which does not involve the transfer of a saving fund from an individual to another. Also, an evolution in the level of specialization and/or in the number of goods may take place in the dynamic equilibrium if the transaction cost coefficient and the degree of economies of specialization and of roundaboutness are neither too large nor too small. If the fixed learning cost in producing tractor is so large that the production of a tractor cannot be completed until time for specialized learning by producing tractor is longer than one

his work, till such time, at least, as both these events can be brought about." 
period, then an explicit saving arrangement which involves a loan from a specialist producer of food to a specialist producer of tractor in period 1 is necessary for specialization in producing roundabout productive tractors.

Under the assumptions of a great fixed learning cost in producing tractors, a small transaction cost coefficient, and significant economies of specialized learning by doing and roundaboutness, dynamic general equilibrium yields the following picture.

A specialist producer of food produces food using his labor only and makes a loan in terms of food to a specialist producer of tractors in period 1 when the production of tractors is not completed. In period 2, a specialist producer of tractors sells tractors to a specialist farmer in excess of the value of his purchase of food in period 2. The difference is his repayment of the loan received in period 1. Per capita consumption of food in period 1 is lower than in an alternative autarkic pattern of organization. But in period 2, tractors are employed to improve productivity of food. The discounted gains will be more than offset the lower level of per capita consumption in period 1 if the transaction efficiency coefficient and economies of specialized learning by doing and roundaboutness are great. Economic growth takes place not only in the sense of an increase in per capita real income between periods, but also in the sense that total discounted real income is higher than in alternative autarkic patterns of organization. ${ }^{4}$ The social organization of division of labor that is created by interpersonal loans and that speeds up specialized learning by doing and increases productivity can be considered as capital in our model.

The model generates the following empirical implications. Returns to investment are higher when division of labor evolves than when the potential for further evolution of division of labor has been exhausted. Hence, the returns to capital in a developing economy experiencing evolution of division of labor are higher than in a developed economy where the potential for the evolution has been nearly exhausted. Since transaction efficiency determines if there is more lucrative opportunity for evolution of division of labor, returns to investment used to develop division of

\footnotetext{
${ }^{4}$ In our model, not only division of labor depends on the extent of the market, but also the extent of the market is determined by the level of division of labor (Allyn Young, 1928). In addition, not only the level of division of labor in roundabout production depends on saving rate, but also returns to saving are dependent on the level of division of labor. These interdependencies, together with interplay between observable prices and production functions in the market and individuals' dynamic decisions in choosing occupation configurations, make our dynamic equilibrium much more complicated than interactions between information and dynamic strategies in sequential equilibrium models. Hence, it is extremely difficult to obtain analytical solutions of comparative dynamics if the decision horizon is long and the number of goods is more than two although theoretically, our analysis can be extended to the case with many goods and very long horizon. One technical difficulty is that no general mathematical method is available for working out the analytical solutions of individuals' dynamic programming problems.
} 
labor are higher in a developing economy with higher transaction efficiency than in a developing economy with low transaction efficiency even if the latter is short of capital compared to the former. In addition our model avoid all kinds of scale effects that are the common features of the AK models and R\&D based models and that are rejected by empirical evidences.

The rest of the paper is organized as follows. Section 2 presents the model. Section 3 solves for dynamic equilibrium. In section 4 , the model is extended to endogenize decision horizon. The final section concludes the paper.

\section{MODEL}

We consider a finite horizon (two-period) economy with $\mathrm{M}$ ex ante identical consumer-producers. There is a single consumer good (called food) produced by labor alone or by labor and an intermediate good (called tractor) together. Individuals can self-provide any goods or alternatively, can purchase them on the market. The self-provided amounts of food and of tractor in period $t$ are denoted respectively $y_{\mathrm{t}}$ and $x_{\mathrm{t}}$. The respective amounts sold and purchased of food in period $\mathrm{t}$ are $y_{\mathrm{t}}^{\mathrm{s}}$ and $y_{\mathrm{t}}^{\mathrm{d}}$, and those of tractor are $x_{\mathrm{t}}^{\mathrm{s}}$ and $x_{\mathrm{t}}^{\mathrm{d}}$. It is assumed that a fraction (1-k) of any shipment of a good disappears in transit due to transaction costs so that $k y_{\mathrm{t}}{ }_{\mathrm{t}}$ is the amount available for consumption after purchasing $y_{\mathrm{t}}{ }_{\mathrm{t}}^{\mathrm{d}}$. The total amount of food consumed by an individual is therefore $y_{\mathrm{t}}+k y_{\mathrm{t}}{ }_{\mathrm{d}}$. Similarly $k x_{\mathrm{t}}^{\mathrm{d}}$ is the amount available of tractor after purchasing $x_{\mathrm{t}}^{\mathrm{d}}$. The total amount of tractor available is therefore $x_{\mathrm{t}}+k x_{\mathrm{t}}^{\mathrm{d}}$. The utility function in period $\mathrm{t}$ is therefore assumed to be equal to natural $\log$ of the amount of food consumed

$$
u_{\mathrm{t}}=\ln \left(y_{\mathrm{t}}+k y_{\mathrm{t}}{ }^{\mathrm{d}}\right) \text {, }
$$

where $u_{\mathrm{t}}$ will be negative infinity if $y_{\mathrm{t}}=y_{\mathrm{t}}{ }^{\mathrm{d}}=0$.

It is assumed that all trade in this economy is mediated through contracts signed in futures markets which operate in period 1. These contracts cannot be renegotiated in some later period. Assume that the futures market horizon and any individual's decision horizon are of two periods. The objective function for an individual's decision problem is therefore total discounted utility, given by:

$$
U=u_{1}+u_{2} /(1+r)
$$

where $U$ is total discounted utility, and $\mathrm{r}$ is a subjective discount rate. 
It is assumed that a fixed learning cost in terms of labor, $A$, is incurred in producing tractor. The fixed learning cost in producing food is $B$. The production functions for an individual are assumed to exhibit economies of specialized learning by doing:

$$
\begin{aligned}
& y_{t}^{p} \equiv y_{t}+y_{t}^{s}=\operatorname{Max}\left\{\left(x_{t}+k x_{t}^{d}\right)^{a}\left(L_{y t}-\sigma B\right), \quad\left(L_{y t}-\sigma B\right)\right\}, \\
& \quad a \in(0,1), B \in(0, l) \\
& x_{t}^{p} \equiv x_{t}+x_{t}^{s}=\operatorname{Max}\left\{\left(L_{x t}-\sigma A\right)^{b}, 0\right\}, \quad b>1, \quad A \in(0, l] \\
& l_{y t}+l_{x t}=l, \quad l_{i t} \in[0, l] \\
& L_{i t}=L_{i t-1}+l_{i t}, \quad L_{x 0}=L_{y 0}=0,{ }^{5}
\end{aligned}
$$

where $y_{\mathrm{t}}+y_{\mathrm{t}}^{\mathrm{s}}$ and $x_{\mathrm{t}}+x_{\mathrm{t}}^{\mathrm{s}}$ are respective total output levels of food and tractor in period $t, l_{\mathrm{it}}$ is the amount of labor allocated to the production of $\operatorname{good} \mathrm{i}(\mathrm{i}=\mathrm{x}, \mathrm{y})$ in period $t$, and $L_{\mathrm{it}}$ is the amount of labor accumulated in producing good $\mathrm{i}$ up to period $t$. We define $l_{\text {it }}$ as a person's level of specialization in producing good $\mathrm{i}$ at $t$. In producing a good in period $t, \sigma=0$ if an individual has engaged in producing the good in period $t-1$ and does not shift between different activities in periods $t$ and $t-1 ; \sigma=1$ if an individual changes jobs in period $t$ or $\mathrm{t}-1$ or engages in producing the good for the first time in period t. Each person is assumed to be endowed with $l$ units of labor in each period. The assumption $A \in(0, l]$ implies it is possible that the production process of tractor cannot be completed in period $\mathrm{t}=1$ if $A=l$, so that a story of investment, saving, and capital may be told. It is assumed that economies of specialized learning-by-doing and the fixed learning cost are specific to each individual and to each activity. The elasticity of output of food with respect to input of tractor $a$ can be interpreted as the degree of type I economies of roundaboutness. Type II of economies of roundabout production are said to exist if labor productivity of food is higher when tractor is employed than when it is not employed. It can be shown that there are type II of economies of roundabout production if the amount of tractor employed by each farmer is sufficiently large and $a$ is large. The amount of tractor per farmer is determined by productivity of tractor, which is in turn dependent on the level of specialization of producers of tractor. But each person's level of specialization is determined by the efficient trade off between economies of specialized learning by doing and transaction costs. Hence, the specification of production functions sets up interdependence between division of labor, production roundaboutness, and transaction costs. We assume that $A+B>l-1$, which implies that self-provision of the two goods by each individual in the two periods is not optimal.

\footnotetext{
${ }^{5}$ It can be assumed that output is 0 if current labor input is 0 even if accumulated past labor input is great (see Borland
} 
A Walras regime prevails because economies of specialized learning by doing are individual specific (increasing returns are localized) and the population size is assumed to be very large, so that competition among many peer specialists in each professional sector nullifies the monopoly power which might occur from specialized learning by doing.

\section{DYNAMIC EQUILIBRIUM AND COMPARATIVE DYNAMICS}

This section considers an individual's production and trade decision problem and dynamic equilibrium. We follow Borland and Yang (1995) to call a profile of zero and positive values of decision variables in each individual's decision problem in a period a configuration. As shown in Borland and Yang (1995), in this kind of models, each individual's dynamic optimum decision is associated with a sequence of configurations over periods. There are six configurations, shown in Figure 1, which constitute four feasible market structures in a period. The circles represent configurations and lines represent flows of goods. ${ }^{6}$

There are two autarky structures E and F, depicted in Fig 1a. In structure E each individual self-provides food without using tractor. In structure F, each individual self-provides both tractor and food.

Two structures involve the division of labor. Structure D consists of configuration (x/y), shown in Fig (a), selling tractor and buying food in a period and configuration (y/x) selling food and buying tractors. Structure $\mathrm{C}$ consists of configuration $(\mathrm{y} / 0)$, which denotes a farmer providing a loan in terms of food, and configuration $(0 / y)$, which denotes a tractor producer receiving food as a loan when he learns how to produce tractor. Feasible structure sequences over two periods are: CD which means structure $\mathrm{C}$ is chosen in period 1 and structure $\mathrm{D}$ is chosen in period 2, DD involving trade and division of labor between specialist producers of tractors and professional farmers over the two periods, EE in which all individuals self-provide food over the two periods, FF where all individuals self-provide tractors and food over the two periods, FE which means each individual self-provides food in period 1 and self-provides tractor and food in period 2. Sequence CD involves explicit saving since a specialist producer of tractor buys food and sells nothing in period

and Yang, 1995). This will avoid unreasonable case that output is positive even if current labor input is 0.

${ }^{6}$ Morishima (1996) used the approach to equilibrium based on corner solutions to prove the existence of Walras' general equilibrium of capital and credit. A recent survey on the literature of inframarginal analysis of endogenous specialization can be found from Yang and S. Ng (1998). A model of endogenous evolution of division of labor with 
1. The one way trade can be considered as a loan made by a specialist farmer to a specialist producer of tractor. Other structure sequences are either infeasible or cannot occur in equilibrium (see Yang 1996 for proof of this statement). Structure sequences are shown in Fig. 2.

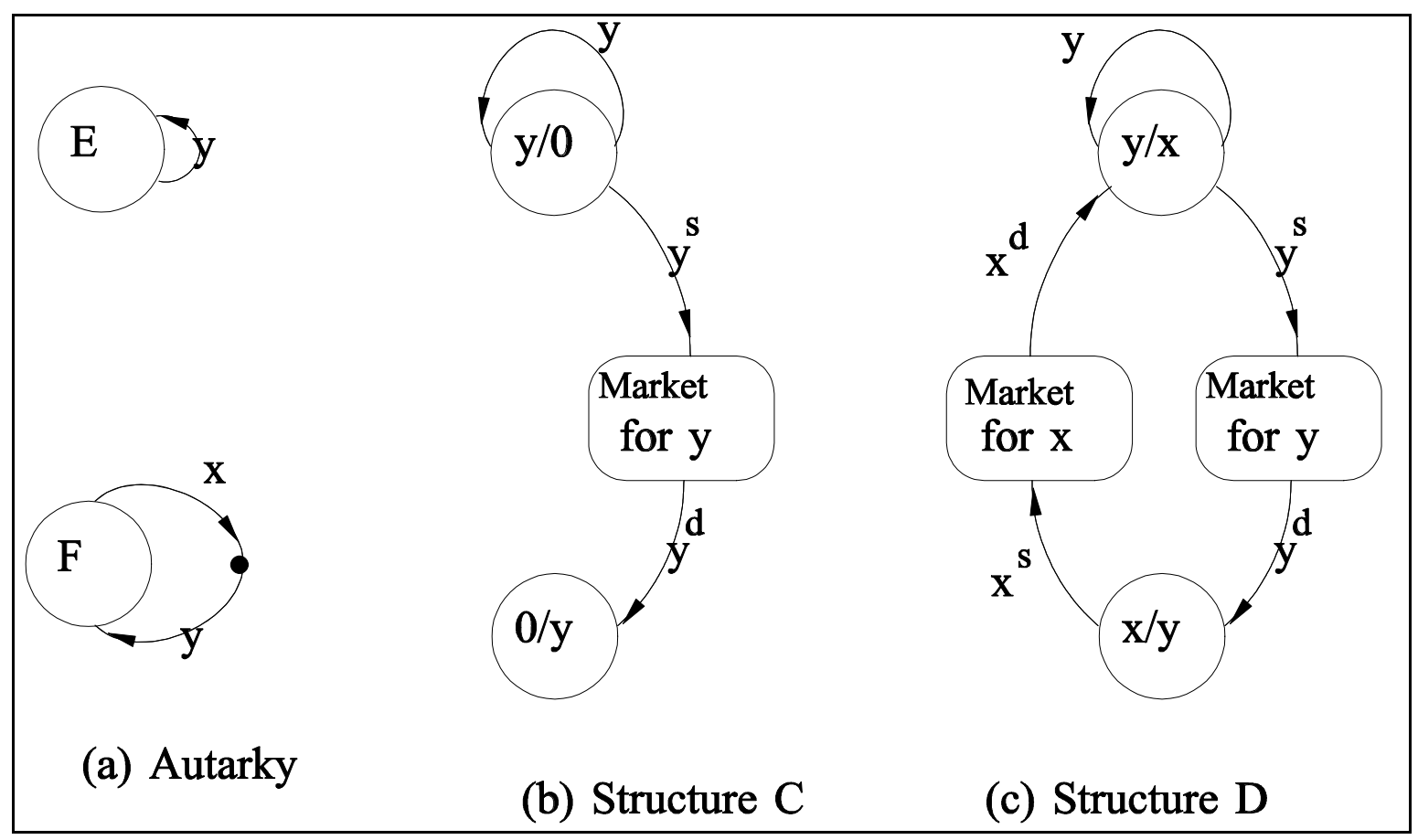

Figure 1: Configurations and Market Structures

A dynamic equilibrium is defined as a fixed point that satisfies the following conditions. (i) For a given profile of the sequences of configurations chosen by individuals, a relative number of individuals choosing different sequences of configurations and a sequence of relative prices of traded goods at different points in time clear the market for goods and equalize total discounted utility of all individuals; (ii) For a given relative number of individuals choosing different sequences of configurations and for a given set of sequences of relative prices of traded goods, individuals maximize total discounted utility with respect to the sequences of configurations and quantities of goods produced, consumed, and traded.

It is possible to solve for the dynamic equilibrium in two steps. First, we solve for a local dynamic equilibrium for each structure sequence. This is given by the market clearing conditions for all traded goods in each period and equalization condition of total discounted utility across infinite horizon can be found from Yang and Borland (1991). 
individuals choosing different configuration sequences. Then, we can compare each individual's total discounted utility under the local equilibrium prices in a given structure sequence between all possible configuration sequences. By the definition of dynamic equilibrium, a local equilibrium in a structure sequence is a general equilibrium if nobody has an incentive to deviate from his configuration sequence in this structure sequence. Hence, the comparisons can be used to identify parameter subspaces within which the local equilibrium in a structure sequence is a general equilibrium.

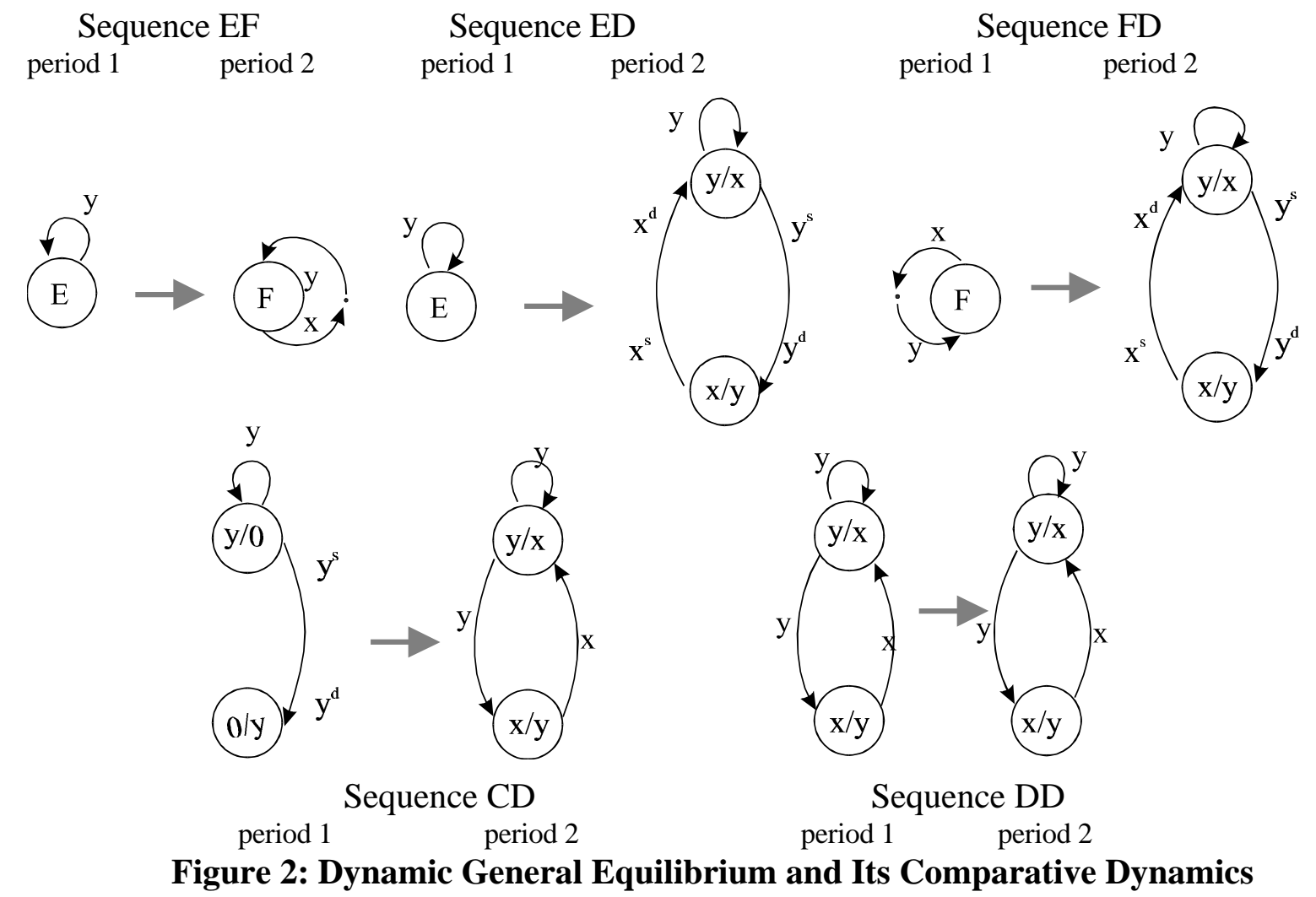

The solution generates comparative dynamics of general equilibrium which describe how dynamic equilibrium jumps between structure sequences as parameter values shift between the parameter subspaces that demarcate structure sequences. The algebra to substantiate this is available from the author upon request. The comparative dynamics are summarized in Table 1.

EE denotes that all individuals self-provide food in the absence of tractors in two periods. EF denotes that all individuals choose autarky in two periods, but they self-provide only food in period 1 and self-provide both food and tractors in period 2. In other words, tractors emerge in period 2 and there is evolution in the number of goods over time. ED denotes that individuals self- 
provide food in period 1 and some of them specialize in producing food and others specialize in producing tractors in period 2. Evolution of division of labor takes place through increases in both individual specialization and the number of goods. FD denotes that individuals self-provide both food and tractors in period 1 and choose specialization and trade of the two goods in period 2. In other words, evolution of division of labor takes place through an increase in individual specialization in the absence of changes in the number of goods. DD denote the division of labor and trade of the two goods in the two periods without its evolution but with an implicit self-saving in period 1. CD denotes the division of labor in the two periods with an explicit saving and a loan in period 1 . All of the evolutionary patterns are shown in Fig. 2.

Table 1: Equilibrium and Its Comparative Dynamics

\begin{tabular}{|c|c|c|c|c|c|c|c|}
\hline \multicolumn{6}{|c|}{$A<l$} & \multicolumn{2}{|c|}{$A=l$} \\
\hline \multicolumn{2}{|l|}{$k$ is small } & \multicolumn{4}{|c|}{$\begin{array}{l}k \text { is large, equilibrium involves division of labor } \\
\text { in the absence of explicit saving }\end{array}$} & $k<k_{0}$ & $k>k_{0}$ \\
\hline$a b<\rho_{0}$ & $a b>\rho_{0}$ & \multicolumn{2}{|c|}{$A+B$ is close to $l$} & \multicolumn{2}{|c|}{$A, B$ are small } & \multirow[b]{3}{*}{$\begin{array}{l}\text { autarky } \\
\text { with only } \\
\text { food } \\
\text { produced } \\
\text { in } 2 \\
\text { periods }\end{array}$} & \multirow{3}{*}{$\begin{array}{l}\text { CD } \\
\text { divisio } \\
\text { of labor } \\
\text { with } \\
\text { explicit } \\
\text { saving }\end{array}$} \\
\hline \multirow[b]{2}{*}{$\begin{array}{l}\text { EE } \\
\text { autarky } \\
\text { with } \\
\text { only } \\
\text { food pro- } \\
\text { duced in } \\
2 \text { periods }\end{array}$} & $\mathrm{EF}$ & $\gamma<\gamma_{1}$ & $\gamma>\gamma_{1}$ & $\gamma<\gamma_{2}$ & $\gamma>\gamma_{2}$ & & \\
\hline & $\begin{array}{l}\text { Autarky } \\
\text { with } \\
\text { tractor } \\
\text { emerging } \\
\text { in } \mathrm{t}=2\end{array}$ & $\begin{array}{l}\text { ED, } \\
\text { evolution } \\
\text { in } \\
\text { speciali- } \\
\text { zation, } \\
\text { tractor } \\
\text { emerges in } \\
t=2\end{array}$ & $\begin{array}{l}\text { DD, } \\
\text { division } \\
\text { of labor } \\
\text { without } \\
\text { evolution }\end{array}$ & $\begin{array}{l}\text { FD, } \\
\text { evolution in } \\
\text { speciali- } \\
\text { zation with } \\
2 \text { goods } \\
\text { produced in } \\
2 \text { periods }\end{array}$ & $\begin{array}{l}\mathrm{DD}, \\
\text { division } \\
\text { of labor } \\
\text { without } \\
\text { evolution }\end{array}$ & & \\
\hline
\end{tabular}

where $\rho_{0} \equiv[\ln (2 l)-\ln (2 l-A)+\ln (a b+1)] /[\ln (2 l-A)-\ln (a b+1)+\ln (a b)]$,

$\gamma_{1} \equiv-[\beta+a b \ln (2 l) /(1+r)] / r, \beta \equiv a(2 \ln k+\ln a)+(1-a) \ln (1-a)$,

$\gamma_{2} \equiv\left[\gamma_{0}-b+a b \ln (2 l) /(1+r)\right](1+r)^{-1}$,

$\gamma_{0} \equiv\{a b \ln [a b(2 l-A-B)+l]+\ln [(a b+2) l-A-B)]+$

$(a b+1)[\ln (l-A-B)-(2+r) \ln (a b+1)]-\ln (2 l)\} /(1+r)+[a b \ln (a b)-\ln (l-B)]$,

$\ln k_{0} \equiv[(2+r) \ln (2+r)-(2-a+r) \ln (2-a+r)-a \ln a-a b \ln (2 l)] / 2 a$.

$\gamma=a b \ln (l-\mathrm{A}) /(1+r)$ increases with the degree of economies of specialization in producing tractor, which is $b$, and with the degree of economies of roundaboutness, which is $a$, and decreases with the discount rate $r$, Here $a b>\rho_{0}$ means that the degree of economies of specialization and roundaboutness is greater than a critical value. $\gamma>\gamma_{i}$ means that the degree of economies of 
specialization and roundaboutness is greater and the discount rate is smaller than some critical values. $k>k_{0}$ means that the transaction efficiency parameter is larger than a critical value. Note that $\gamma_{1}$ and $\gamma_{2}$ decrease as $k$ increases, so that DD is more likely to be equilibrium compared to ED or FD if transaction efficiency is higher. Also, $k_{0}$ decreases with $a b$, so that CD is more likely to be equilibrium compared to $\mathrm{EE}$ if the degree of economies of specialization and roundaboutness is greater.

Table 1 provides a characterization of the conditions under which the various sequences of market structures will constitute the dynamic equilibrium. There are five parameters that determine the comparative dynamics of the equilibrium: A (fixed learning cost in producing tractor), $\mathrm{B}$ (fixed learning cost in producing food), $k$ (transaction efficiency), $a b$ (degree of economies of specialization and roundaboutness), and $r$ (discount rate). Transaction efficiency determines whether specialization is more likely to take place in the equilibrium compared to autarky. Fixed learning cost $A$ determines whether an explicit saving is essential for the division of labor. If $A$ is small, then explicit saving and a loan between individuals are not necessary for the division of labor. When individual specialization and related trade takes place in DD, there is an implicit investment for increasing specialization, which is in terms of a decrease in consumption of food in period 1 (compared to consumption of food in an alternative autarkic structure), caused by a larger transaction cost. However, such investment does not involve the transfer of investment funds between individuals. Hence, investment comes from self-savings rather than from commercial savings. If $A=l$, then explicit saving and a loan between individuals are necessary for the division of labor. If $A<l$ but $A+B$ is close to $l$, then FD is infeasible and ED will be equilibrium provided k is large and $a b$ is not great compared to $r$. The degree of economies of specialization and roundaboutness $a b$ determines whether a larger number of goods and/or a higher level of specialization is more likely to take place in the equilibrium. Gradual evolution in individual specialization and/or in the number of goods will take place in the equilibrium if $k$ is large but $a b$ is small compared to $r$, or if $k$ is small but $a b$ is large. A larger discount rate $r$ will make a small number of goods and a low level of specialization more likely to take place in the equilibrium.

It is interesting to see that increases in the extent of the market, in trade dependence, in the extent of endogenous comparative advantage, in productivity, in the degree of production roundaboutness, in the variety of goods and different professions, in the degree of production concentration, and in the degree of market integration are different aspects of the evolution in 
division of labor. Detailed discussion of the concurrent phenomena can be found from Borland and Yang (1995) and Yang and $\mathrm{Ng}$ (1993).

If transaction efficiency, $k$, and the fixed learning cost, $A$, are sufficiently large, then equilibrium sequence is $\mathrm{CD}$ where a loan in terms of food is made from a professional farmer to a professional producer of tractor in period 1 and repaid in terms of tractor in period 2. It can be shown that in this structure sequence a farmer's saving level and saving rate in period 1 increase with the degree of economies of roundaboutness, and decrease with the subjective discount rate. But more importantly, transaction efficiency $k$ determines if $\mathrm{CD}$ or EE is equilibrium. If transaction efficiency $k$ is very small due to a deficient tax system or a deficient legal system, then EE instead of $\mathrm{CD}$ will be equilibrium, which implies a zero saving rate. Also, the magnitude of the fixed learning cost determines whether implicit or explicit saving is essential for a high growth rate of per capita real income.

The real saving level in CD can be calculated as the difference in utility between EE and $\mathrm{CD}$ in period 1 . The real return on the saving can be calculated from the difference in discounted utility between $\mathrm{CD}$ and $\mathrm{EE}$ in period 2. Again, there are two types of comparative dynamics of the equilibrium. If values of the parameters of transaction efficiency and economies of specialization and roundaboutness decline to have reached a threshold level, then dynamic equilibrium shifts from $\mathrm{CD}$ to $\mathrm{EE}$ (autarky), real returns to saving jump down to zero. The second type of comparative dynamics are that as the parameters change within the range defined by the threshold values such that equilibrium stays in $\mathrm{CD}$, then it can be shown that the real interest rate increases with transaction efficiency and with the degree of economies of specialization. This result can be used to theorize the successful practice of the Hongkong and Taiwan governments in carrying out a liberalization and internationalization policy which stimulates investment and trade by reducing $\operatorname{tax}$.

The theory of capital and investment can be used to explain a sudden decline of interest rates. Suppose that transaction efficiency coefficient and the fixed learning cost are sufficiently large, so that $\mathrm{CD}$ is equilibrium and the saving rate and real interest rate on the saving are positive. However, if the decision horizon is longer than two periods, then the opportunity for investment will suddenly disappear in period $t>2$ as structure $\mathrm{D}$, which is the highest level of division of labor in the model, has been reached. If the number of goods is more than 2 in the model, then more opportunity for lucrative investment may last longer than two periods. However, there is a limit for 
the evolution in division of labor. For instance, the number of professional sectors cannot be larger than the population size, so that the highest level of division of labor will be eventually reached and no more opportunity for investment for increasing division of labor can be pursued if the number of professional sectors is close to the population size. This is an interesting explanation of a decline in interest rates, which is consistent with classical theory of capital based on the intimate connection between capital and division of labor, but is substantially different from Keynes' (1936) view of interest rates which focuses on the implication of pure consumers' preference for liquidity.

\section{ENDOGENOUS HORIZON}

If the decision horizon is a decision variable and uncertainty of realizing the gains from investment is introduced, there is another interesting tradeoff between gains from a longer decision horizon which can amortize investment cost over a longer period of time and a decreasing probability for realizing the gains. Suppose the fixed learning $\operatorname{cost} A=l$ in an extended model which is the same as the original one except that the decision horizon $n$ is each individual's decision variable. The discount rate is assumed to be zero and $l$ is assumed to be 1 for simplicity. The probability that gains of total discounted utility from a sequence with the division of labor and savings are realized is $f(n)=1 / n$ and the probability that the gain is zero is $1-f(n)$. Each individual maximizes expected gains in terms of total discounted utility from choosing the division of labor. Then, it can be shown that the necessary condition for the equilibrium decision horizon is equivalent to the first order condition for maximizing

$$
\begin{aligned}
& V=f(n) F(n, k, a, b), \\
& F(n, k, a, b)=\{[n-a(n-1)] \ln [n-a(n-1)]+a(n-1)(\ln 2+\ln a+2 \ln k)+b[0.5(1+n) n-1]\}
\end{aligned}
$$

where $F$ is the difference in total utility over n periods between division of labor and autarky. Application of the envelope theorem to $V=f(n) F(n, k, a, b)$ and the implicit function theorem to $F$ yields comparative dynamics:

$$
\mathrm{d} n^{*} / \mathrm{d} k=-\left(\partial^{2} V / \partial k \partial n\right) /\left(\partial^{2} V / \partial n^{2}\right)>0, \text { and } \mathrm{d} V\left(n^{*}, k\right) / \mathrm{d} k=\partial V\left(n^{*}, k\right) / \partial k>0
$$

where $\partial^{2} V / \partial k \partial n>0, \partial^{2} V / \partial n^{2}<0 . n^{*}$ is the equilibrium decision horizon, which efficiently trades off the gains from a longer horizon against a decreasing probability for realizing them. The policy implication of the result is straightforward. A liberalization and internationalization policy which reduces tariff or a better legal system which improves transaction conditions will increase 
individuals' efficient decision horizon and increase opportunity for lucrative investment for increasing division of labor.

\section{CONCLUSION}

This paper uses a dynamic general equilibrium model based on corner solutions to show that investment does not necessarily increase future productivity. Productivity in the future can be increased by an investment that is used to create a higher level of division of labor which can speed up accumulation of professional experience (human capital) through specialized learning by producing roundabout productive equipment or services. Self-saving is enough for investment in raising division of labor if the fixed learning cost in roundabout productive activities is not large. A loan from a producer of consumption goods to specialist producers of producer goods is essential for such investment if the fixed learning cost is large. If the transaction cost coefficient is large due to a deficient legal system or to a protectionist tariff, such opportunity for lucrative investment for increasing division of labor does not exist, so that investment may not increase real income. A decrease in the degree of economies of specialization and roundaboutness, an increase in the transaction cost coefficient, and/or exhaustion of the potential for further evolution of division of labor will reduce real return rates on investment and reduce opportunity for lucrative investment.

Sachs and Warner (1995) provide preliminary empirical evidence for our model. They use cross-country data to show that growth performance (and therefore related returns to capital) is positively affected by an index of institutional quality that affects transaction conditions. Gallups and Sachs (1998) shows the population share of coast region and other geographical conditions that affect transaction conditions positively contribute to growth performance too. 


\section{APPENDIX: PROOF OF COMPARATIVE DYNAMICS OF EQUILIBRIUM}

We use structure sequence $C D$, in which structure $C$ is chosen in period 1 and $D$ is chosen in period 2, to show how to solve for a local dynamic equilibrium in a given structure sequence. The structure $\mathrm{C}$ consists of configurations $(0 / \mathrm{y})$ and $(\mathrm{y} / 0)$ and structure $\mathrm{D}$ consists of configurations $(\mathrm{x} / \mathrm{y})$ and $(\mathrm{y} / \mathrm{x})$. Hence, this structure sequence consists of the sequence of configurations $(0 / \mathrm{y})$ and $(\mathrm{x} / \mathrm{y})$ and the sequence of configurations $(\mathrm{y} / 0)$ and $(\mathrm{y} / \mathrm{x})$. There are two steps in solving for the local equilibrium in the structure sequence: first, for each sequence of configurations the utility-maximizing labor allocation decision and demands and supplies for each good in each period (and hence the indirect total discounted utility of an individual who chooses that configuration sequence) are derived; and second, given the demands, supplies, and indirect utility function of an individual in each configuration sequence, the market clearing conditions and utility equalization conditions are used to solve for the set of corner equilibrium relative prices and number of individuals choosing different configuration sequences.

Sequence of Configurations (0/y) and (x/y): In this sequence $\mathrm{x}_{2}{ }^{\mathrm{s}}, \mathrm{y}_{\mathrm{t}}{ }^{\mathrm{d}}>0,1_{\mathrm{xt}}=l$, and $\mathrm{x}_{1}{ }^{\mathrm{s}}=\mathrm{x}_{\mathrm{t}}=1_{\mathrm{yt}}=$ $\mathrm{y}_{\mathrm{t}}=\mathrm{x}_{\mathrm{t}}{ }^{\mathrm{d}}=\mathrm{y}_{\mathrm{t}}{ }^{\mathrm{s}}=0$. This sequence will be chosen by an individual only if $\mathrm{A}=l$ which means that the production process of a tractor cannot be completed in period 1 due to the large fixed learning cost. If $A<l$, a sequence of $(x / y)$ over two periods will be chosen since it does not make sense to choose $(0 / y)$ which delays sale of tractor when a tractor can be produced out in period 1 . Hence, we assume $A=l$ in this configuration sequence, so that the decision problem for sequence of (0/y) and $(\mathrm{x} / \mathrm{y})$ is:

$$
\begin{array}{cl}
\underset{\mathrm{y}_{\mathrm{t}}{ }_{\mathrm{d}}}{\operatorname{Max}:} & \mathrm{U}=\ln \left(\mathrm{ky}_{1}{ }^{\mathrm{d}}\right)+\ln \left(\mathrm{ky}_{2}{ }^{\mathrm{d}}\right) /(1+\mathrm{r}) \\
\text { subject to: } & \mathrm{x}_{1}{ }^{\mathrm{s}}=0 \text { and } \mathrm{x}_{2}{ }^{\mathrm{s}}=\left(\mathrm{l}_{\mathrm{x} 1}+\mathrm{l}_{\mathrm{x} 2}\right)^{\mathrm{b}} \\
& 1_{\mathrm{x} 1}=1_{\mathrm{x} 2}=l \\
& \mathrm{p}_{\mathrm{x} 2} \mathrm{x}_{2}{ }^{\mathrm{s}}=\mathrm{y}_{1}{ }^{\mathrm{d}}+\mathrm{p}_{\mathrm{y} 2} \mathrm{y}_{2}{ }^{\mathrm{d}}
\end{array}
$$

(production function)

(endowment constraint)

(budget constraint)

where $p_{i t}$ is the price of good $i$ in period $t$ in terms of food in period 1 which is assumed to be the numeraire and $\mathrm{y}_{1}{ }^{\mathrm{d}}$ is a loan in terms of food made by a specialist farmer to the specialist producer of tractor. The specialist tractor producer's sale in periods $2, \mathrm{p}_{\mathrm{x} 2} \mathrm{x}_{2}{ }^{\mathrm{s}}$, is greater than his purchase in period $2, p_{\mathrm{y} 2} \mathrm{y}_{2}{ }^{\mathrm{d}}$. The difference is repayment of the loan. The solution to $(6 \mathrm{a})$ is

$$
\mathrm{x}_{2}{ }^{\mathrm{s}}=(2 l)^{\mathrm{b}}, \quad \mathrm{y}_{1}{ }^{\mathrm{d}}=(1+\mathrm{r})(2 l)^{\mathrm{b}} \mathrm{p}_{\mathrm{x} 2} /(2+\mathrm{r}), \quad \mathrm{y}_{2}{ }^{\mathrm{d}}=(2 l)^{\mathrm{b}} \mathrm{p}_{\mathrm{x} 2} /(2+\mathrm{r}) \mathrm{p}_{\mathrm{y} 2},
$$




$$
\mathrm{U}_{\mathrm{x}}=\left\{(2+\mathrm{r})\left[\operatorname{lnk}+\mathrm{b} \ln (2 l)+\ln \mathrm{p}_{\mathrm{x} 2}-\ln (2+\mathrm{r})\right]-\ln \mathrm{p}_{\mathrm{y} 2}\right\} /(1+\mathrm{r})+\ln (1+\mathrm{r}),
$$

where $x_{t}{ }^{s}$ and $y_{t}{ }^{d}$ are supply of tractor and demand for food in period $t$, respectively, $U_{x}$ is the indirect total discounted utility function for the sequence.

Sequence of $(y / 0)$ and $(y / x):$ By a similar process, the optimum decision for this sequence can be found as follows.

$$
\begin{aligned}
\mathrm{x}_{2}{ }^{\mathrm{d}} & =\left(2 \mathrm{ak}^{\mathrm{a}} l \mathrm{p}_{\mathrm{y} 2} / \mathrm{p}_{\mathrm{x} 2}\right)^{1 /(1-\mathrm{a})}, \quad \mathrm{y}_{1}^{\mathrm{s}}=\left\{l-\mathrm{B}-(1+\mathrm{r})(1-\mathrm{a})\left[2 \mathrm{p}_{\mathrm{y} 2} l\left(\mathrm{ak} / \mathrm{p}_{\mathrm{x} 2}\right)^{\mathrm{a}}\right]^{1 /(1-\mathrm{a})}\right\} /(2+\mathrm{r}) \\
\mathrm{y}_{2}{ }^{\mathrm{s}}= & \left\{(1+\mathrm{a}+\mathrm{r})\left[2 l\left(\mathrm{p}_{\mathrm{y} 2} \mathrm{ak} / \mathrm{p}_{\mathrm{x} 2}\right)^{\mathrm{a}}\right]^{1 /(1-\mathrm{a})}-(l-\mathrm{B}) / \mathrm{p}_{\mathrm{y} 2}\right\} /(2+\mathrm{r}), \\
\mathrm{U}_{\mathrm{y}}= & (2+\mathrm{r})\left[\ln \left\{l-\mathrm{B}+(1-\mathrm{a})\left[2 \mathrm{p}_{\mathrm{y} 2} l\left(\mathrm{ak} / \mathrm{p}_{\mathrm{x} 2}\right)^{\mathrm{a}}\right]^{1 /(1-\mathrm{a})}\right\}-\ln (2+\mathrm{r})\right] /(1+\mathrm{r}) \\
& +\ln (1+\mathrm{r})-\ln \mathrm{p}_{\mathrm{y} 2} /(1+\mathrm{r})
\end{aligned}
$$

where $U_{y}$ is the indirect total discounted utility function for the sequence.

Utility maximization by individuals and the assumption of free entry (when individuals make decisions at $\mathrm{t}=1$ ) have the implication that the total discounted utility of individuals is equalized across the two sequences of configurations. That is,

$$
\mathrm{U}_{\mathrm{x}}=\mathrm{U}_{\mathrm{y}}
$$

Let $\mathrm{M}_{\mathrm{i}}$ represent the number of individuals selling good i. Multiplying $\mathrm{M}_{\mathrm{i}}$ by individual demands and supplies gives market demands and supplies. The market clearing conditions for the two goods over two periods are:

$$
\mathrm{M}_{\mathrm{x}} \mathrm{x}_{2}{ }^{\mathrm{s}}=\mathrm{M}_{\mathrm{y}} \mathrm{x}_{2}{ }^{\mathrm{d}}, \mathrm{M}_{\mathrm{x}} \mathrm{y}_{\mathrm{t}}{ }^{\mathrm{d}}=\mathrm{M}_{\mathrm{y}} \mathrm{y}_{\mathrm{t}}^{\mathrm{s}}, \mathrm{t}=1,2
$$

where $\mathrm{M}_{\mathrm{x}} \mathrm{x}_{2}{ }^{\mathrm{s}}$ and $\mathrm{M}_{\mathrm{y}} \mathrm{x}_{2}{ }^{\mathrm{d}}$ are market supply and demand, respectively, for tractor in period 2, and $\mathrm{M}_{\mathrm{x}} \mathrm{y}_{\mathrm{t}}^{\mathrm{d}}$ and $\mathrm{M}_{\mathrm{y}} \mathrm{y}_{\mathrm{t}}^{\mathrm{s}}$ are market demand and supply, respectively, for food in period $\mathrm{t}$. Note that due to Walras' law one of the three market clearing conditions is not independent of others. There are three independent equations generated by the market clearing and utility equalization conditions, which determine three unknown variables: $M_{x} / M_{y}, p_{x 2}, p_{y 2}$, where $p_{i t}$ is the price of good $i$ in period $t$ in terms of food in period 1 and $M_{i}$ can be solved using the population size equation $M=M_{x}+M_{y}$ as soon as $\mathrm{M}_{\mathrm{x}} / \mathrm{M}_{\mathrm{y}}$ is determined. The corner equilibrium values of the three variables are thus given as follows.

$$
\begin{aligned}
& \mathrm{p}_{\mathrm{x} 2}=(2-\mathrm{a}+\mathrm{r})(l-\mathrm{B}) /(1+\mathrm{r}) \mathrm{k}(2 l)^{\mathrm{b}}, \mathrm{p}_{\mathrm{y} 2}=\left[(2-\mathrm{a}+\mathrm{r}) / \mathrm{ak}^{2}(2 l)^{\mathrm{b}}\right]^{\mathrm{a}}(l-\mathrm{B}) /(1+\mathrm{r})(2 l)^{1+\mathrm{ab}}, \\
& \mathrm{M}_{\mathrm{x}} / \mathrm{M}_{\mathrm{y}}=\mathrm{ak} /(2-\mathrm{a}+\mathrm{r}) \\
& \mathrm{U}(\mathrm{CD})=\ln (l-\mathrm{B})+[(2-\mathrm{a}+\mathrm{r}) \ln (2-\mathrm{a}+\mathrm{r})-(2+\mathrm{r}) \ln (2+\mathrm{r}) \\
& \quad+(\mathrm{ab}+1) \ln (2 l)+\mathrm{a}(\ln \mathrm{a}+2 \operatorname{lnk})] /(1+\mathrm{r})
\end{aligned}
$$


where $\mathrm{U}(\mathrm{CD})$ is the maximum total discounted utility for structure sequence $\mathrm{CD}$, which is derived by inserting the corner equilibrium relative prices into the expression for indirect total discounted utility.

Following the procedure to solve for the local equilibrium in market sequence $\mathrm{CD}$, total discounted utility levels in all market sequences can be derived as follows.

$$
\text { (A1) } \begin{aligned}
& U(\mathrm{EE})=\ln (2 l) /(1+r)+\ln (l-B) \\
& U(\mathrm{FF})= {[(2+r) /(1+r)][a b \ln (a b)-(a b+1) \ln (a b+1)]+} \\
& {[(a b+1) /(1+r)][(1+r) \ln (l-A-B)+\ln (2 l-A-B)] } \\
& \mathrm{U}(\mathrm{EF})=\{a b \ln (a b)+(a b+1)[\ln (2 l-A)-\ln (a b+1)]\} /(1+r)+\ln (l-B) \\
& \mathrm{U}(\mathrm{ED})=\{a(2 \ln k+\ln a)+(1-a) \ln (1-a)+a b \ln (l-A)+\ln (2 l)\} /(1+r)+\ln (l-B) \\
& \mathrm{U}(\mathrm{FD})=\{a(2 \ln k+\ln a)+(1-a) \ln (1-a)+a b \ln [a b(2 l-A-B)+l]+\ln [(a b+2) l-A-B]\} /(1+r) \\
&+a b \ln (a b)+(a b+1)[\ln (l-A-B)-(2+r) \ln (a b+1) /(1+r)] \\
& \mathrm{U}(\mathrm{DD})=(2+r)\{a(2 \ln k+\ln a)+(1-a) \ln (1-a)\} /(1+r)+a b \ln (l-A) \\
&+ \ln (l-B)+[(1+a b) \ln (2 l) /(1+r)] \\
& \mathrm{U}(\mathrm{CD})=\ln (l-B)+[(2-a+\mathrm{r}) \ln (2-a+\mathrm{r})-(2+r) \ln (2+r) \\
&+(a b+1) \ln (2 l)+a(\ln a+2 \ln k)] /(1+r)
\end{aligned}
$$

Following the method used by Sun, Yang, and Yao (1998), we can prove that in this model the general equilibrium is the local equilibrium that generates the highest total discounted utility. Hence, comparisons between utilities in different structure sequences can partition the parameter space into subspaces within each of which a particular structure sequence occurs in equilibrium.

Here we exclude infeasible sequences, such as EC, FC, CE, CF, and CC, which are incompatible with the budget constraint. Also, those sequences that are obviously incompatible with equilibrium are excluded. For instance, all sequences that involve devolution in specialization or in the number of goods cannot generate the highest total discounted utility because they cannot exploit economies of specialized learning by doing and economies of roundaboutness nor save on transaction costs in period 1 compared to alternative sequences. (A1) shows that total discounted utility levels in all structure sequences with the division of labor are increasing functions of $\ln k$. Hence, they tend to negative infinity as k converges to zero, and lnk tends to zero as k converges to one. But all structure sequences with autarky are independent of $\mathrm{k}$. This implies that all sequences 
with division of labor (ED, FD, DD, CD, and others with $\mathrm{D}$ or $\mathrm{C}$ ) cannot be equilibria and only autarkic sequences (EE, FF, and EF) can be candidates for general equilibrium if $\mathrm{k}$ is sufficiently close to zero. We consider first the case with a value of $\mathrm{k}$ that is sufficiently close to zero, then the case with a value of $\mathrm{k}$ that is sufficiently close to one.

(1) Parameter k is sufficiently close to 0 , so that only EE, FF, and EF need to be considered.

(i) A comparison between $\mathrm{U}(\mathrm{EF})$ and $\mathrm{U}(\mathrm{FF})$ indicates that $\mathrm{U}(\mathrm{EF})>\mathrm{U}(\mathrm{FF})$ holds if $A+B>l-1$ which is assumed in the model. Therefore, FF cannot be a general equilibrium.

(ii) A comparison between $\mathrm{U}(\mathrm{EF})$ and $\mathrm{U}(\mathrm{EE})$ yields

$$
\begin{aligned}
& \mathrm{U}(\mathrm{EF})>\mathrm{U}(\mathrm{EE}) \\
& \text { iff } \mathrm{ab}>\rho_{0} \equiv[\ln (2 l)-\ln (2 l-\mathrm{A})+\ln (\mathrm{ab}+1)] /[\ln (2 l-\mathrm{A})-\ln (\mathrm{ab}+1)+\ln (\mathrm{ab})]
\end{aligned}
$$

where $\rho_{0}$ decreases with ab, which implies that EF is more likely to be equilibrium compared to EE if $a b$ is larger. $\rho_{0}$ becomes negative and $a b>\rho_{0}$ certainly holds if $b$ is sufficiently large. $\rho_{0}$ is a positive number smaller than one if ab is sufficiently small. For the latter case, $U(E E)>U(E F)$ becomes possible.

(2) Parameter $\mathrm{k}$ is sufficiently close to 1.

(i) A is not close to $l$.

(ia) Assume that $\mathrm{B}<l, \mathrm{~A}+\mathrm{B}$ is sufficiently close to $l$, and $\mathrm{k}$ is not very large; then $\mathrm{U}(\mathrm{FD})$ tends to be negative and FD cannot be equilibrium. A comparison between U(ED) and $\mathrm{U}(\mathrm{DD})$ yields

$$
\mathrm{U}(\mathrm{DD})>\mathrm{U}(\mathrm{ED}) \text { iff } \gamma>\gamma_{1}
$$

where $\gamma=a b \ln (l-\mathrm{A}) /(1+r)$ and $\gamma_{1} \equiv-[\beta+a b \ln (2 l) /(1+r)] / r, \beta \equiv a(2 \ln k+\ln a)+(1-\mathrm{a}) \ln (1-\mathrm{a})$.

(ib) Assume that $\mathrm{A}$ and $\mathrm{B}$ are not too large and $\mathrm{k}$ is close to 1 , then

$$
\gamma_{0}>\gamma_{1}
$$

where $\gamma_{0} \equiv\{a b \ln [a b(2 l-A-B)+l]+\ln [(a b+2) l-A-B)]+$ $(a b+1)[\ln (l-A-B)-(2+r) \ln (a b+1)]-\ln (2 l)\} /(1+r)+[a b \ln (a b)-\ln (l-B)]$.

Comparisons between $\mathrm{U}(\mathrm{ED}), \mathrm{U}(\mathrm{FD})$, and $\mathrm{U}(\mathrm{DD})$ yield

$$
\begin{aligned}
& \mathrm{U}(\mathrm{ED})>\mathrm{U}(\mathrm{FD}) \text { iff } \gamma>\gamma_{0} \\
& \mathrm{U}(\mathrm{DD})>\mathrm{U}(\mathrm{ED}) \text { iff } \gamma>\gamma_{1} \\
& \mathrm{U}(\mathrm{DD})>\mathrm{U}(\mathrm{FD}) \text { iff } \gamma>\gamma_{2}
\end{aligned}
$$


where $\gamma_{2} \equiv\left[\gamma_{0}-\beta+a b \ln (2 l) /(1+r)\right](1+r)^{-1}$. (A5) implies that $E D$ can be equilibrium only if $\mathrm{U}(\mathrm{ED})>\mathrm{U}(\mathrm{FD}), \mathrm{U}(\mathrm{DD})$, or only if $\gamma_{1}>\gamma_{0}$, which contradicts (A4). Hence, under the assumption (ib), ED cannot be equilibrium. Thus, under the assumption (ib)

(A6) $\quad$ DD is general equilibrium if $\gamma>\gamma_{2}$ and FD is equilibrium if $\gamma<\gamma_{2}$

(ii) Assume that $\mathrm{A}=l$; then only $\mathrm{EE}$ and $\mathrm{CD}$ are feasible. A comparison between $\mathrm{U}(\mathrm{CD})$ and $\mathrm{U}(\mathrm{EE})$ yields

(A7) $\quad \mathrm{U}(\mathrm{CD})>\mathrm{U}(\mathrm{EE})$ iff $\mathrm{k}>\mathrm{k}_{0}$ where $\ln k_{0} \equiv[(2+\mathrm{r}) \ln (2+\mathrm{r})-(2-\mathrm{a}+\mathrm{r}) \ln (2-\mathrm{a}+\mathrm{r})-\mathrm{alna}-\mathrm{ab} \ln (2 l)] / 2 \mathrm{a}$. (A1)-(A7) are sufficient for establishing comparative dynamics of equilibrium in Table 1. 


\section{REFERENCES}

Aghion, Philippe and Peter Howitt (1992): “A Model of Growth Through Creative Destruction”, Econometrica, 60, 323-351.

Barro, R. (1991): "Economic Growth in a Cross Section of Countries", Quarterly Journal of Economics, 106(2), 407443.

Barro, R. and Sala-i-Martin, X. (1995): Economic Growth, New York, McGraw-Hill.

Benhabib, J. and Joranovic, B. (1991): "Externalities and Growth Accounting”, American Economic Review, 81, 82113.

Borland, Jeff and Yang, Xiaokai (1995): "Specialization, Product Development, Evolution of the Institution of the Firm, and Economic Growth," Journal of Evolutionary Economics, 4, 19-42.

Dasgupta, P. (1995): “The Population Problem: Theory and Evodence." Journal of Economic Literature, $33,1879-1902$.

Gallup, John and Jeff Sachs (1998), "Geography and Economic Development," Working Paper no. 1, Center for International Development at Harvard University.

Grossman, Gene M., and Helpman, Elhanan (1989): "Product Development and International Trade", Journal of Political Economy, 97, 1261-1283.

Grossman, Gene M., and Helpman, Elhanan (1990): "Comparative Advantage and Long-Run Growth", American Economic Review, 80, 796-815.

Grossman, G. and Helpman, E. (1991), "Quality Ladders and Product Cycles", Quarterly Journal of Economics, 106, 557-86.

Jones, C.I. (1995a): “Time Series Tests of Endogenous Growth Models”, Quarterly Journal of Economics, 110, 695525.

Jones, C.I. (1995b): “R \& D-Based Models of Economic Growth”, Journal of Political Economy, 103, 759-784.

Josephson, Matthew (1959), Edison; a Biography, New York, McGraw-Hill.

Judd, K. (1985): "On the Performance of Patents", Econometrica, 53, 579-85.

Keynes, John (1936), The General Theory of Employment, Interest and Money, London, Macmillan.

Lucas, Robert E. Jr. (1988): "On the Mechanics of Economic Development", Journal of Monetary Economics, 22, $3-42$.

Marshall, Alfred (1890), Principles of Economics, 8th Edition, New York, Macmillan, 1948.

Morishima, Michio (1996), Dynamic Economic Theory. Translation. Cambridge, Cambridge University Press.

Pritchett, Lant (1997), “Where Has all the Education Gone?” The World Bank Policy Research Working Paper.

Ramsey, Frank (1928): "A Mathematical Theory of Saving", Economic Journal, 38, 543-59.

Rebelo, S. (1991): “Long-Run Policy Analysis and Long-Run Growth”, Journal of Political Economy, 99: 500-521. 
Romer, Paul M. (1986): "Increasing Returns and Long-Run Growth", Journal of Political Economy, 94, 1002-1037.

Romer, P. (1987): "Increasing Returns, Specialization, and External Economies: Growth as Described by Allyn Young", American Economic Review, Papers and Proceedings.

Romer, Paul M. (1990): "Endogenous Technical Change", Journal of Political Economy, 98, S71-S102.

Sachs, J. and Warner, A. (1995) “Economic Reform and the Process of Global Integration,” Brookings Papers on Economic Activity, 1.

Sachs, Jeffrey and Warner, Andrew (1997): "Fundamental Sources of Long-Run Growth." American Economic Review, Papers and Proceedings, 87, 184-88.

Smith, Adam (1776), An Inquiry into the Nature and Causes of the Wealth of Nations. Reprint, edited by E. Cannan. Chicago: University of Chicago Press, 1976.

Solow, Robert (1964), Capital Theory and the Rate of Return, Tand McNally.

Solow, Robert (1956), "A Contribution to the Theory of Economic Growth," Quarterly Journal of Economics, 70, 6594.

Sun, Yang, and Yao (1998), “General Equilibrium Network of Division of Labor," Seminar Paper, Department of Economics, Monash University.

Yang, Xiaokai (1996): "The Division of Labor and the Nature of Capital." Seminar Paper, Department of Economics, Monash University.

Yang, Xiaokai, and Borland, Jeff (1991): "A Microeconomic Mechanism for Economic Growth", Journal of Political Economy, 99, 460-482.

Yang, Xiaokai, and Ng, Y-K (1993): Specialization and Economic Organization, Amsterdam, North-Holland.

Yang, Xiaokai and Ng, Siang (1998): “Specialization and Division of Labor: A Survey,” in K. Arrow, Y-K. Ng, and X. Yang (eds.), Increasing Returns and Economic Analysis, London, Macmillan.

Yang, X., Wang, J., and Wills, I. (1992), "Economic Growth, Commercialization, and Institutional Changes in Rural China, 1979-1987", China Economic Review, 3, 1-37.

Young, Allyn (1928): "Increasing Returns and Economic Progress", Economic Journal, 38, 527-42.

Young, Alwyn (1998), “Growth without Scale Effects," Journal of Political Economy, 106, 41-63. 